\title{
Awareness of Toxicological Impact and Risk of using Talcum Powder as a factor for Ovarian Cancer among Women in three Metropolitan Cities of Southwestern States of Nigeria
}

\section{Koleayo Oluwafemi Omoyajowo}

Department of Cell Biology and Genetics, University of Lagos, Nigeria https://orcid.org/0000-00029860-4931

\section{Amos Lanreyebi Ogunyebi}

Department of Cell Biology and Genetics, University of Lagos, Nigeria https://orcid.org/0000-00032315-470X

\section{Olapeju Aarinola Adenekan}

Department of Science Policy and Innovation Studies, National Centre for Technology Management, Lagos, Nigeria

Tolulope I. Bakare ( $\nabla$ tolu.bakare.tb@gmail.com )

African Institute for Science Policy and Innovation, Obafemi Awolowo University, Ile-Ife, Nigeria

\section{Busayo Omoyajowo}

Department of Chemistry, Ekiti State University, Ado-Ekiti

\section{Oluwaseun Emmanuel Odipe}

Department of Environmental and Occupational Health Science, School of Public Health, University of Medical Sciences, Ondo https://orcid.org/0000-0002-0732-2622

Ibitayo Abiola Samuel

Department of Environmental Health Science, Kwara State University, Malete

\section{Research Article}

Keywords: Risk Perception, Talcum powder, Ovarian Cancer, Advocacy, Nigerian Women

Posted Date: July 7th, 2021

DOl: https://doi.org/10.21203/rs.3.rs-679934/v1

License: (c) (1) This work is licensed under a Creative Commons Attribution 4.0 International License. Read Full License 
Version of Record: A version of this preprint was published at Journal of Applied Sciences and Environmental Management on November 22nd, 2021. See the published version at https://doi.org/10.4314/jasem.v25i7.14. 


\title{
Awareness of Toxicological Impact and Risk of using Talcum Powder as a factor for Ovarian
}

\section{Cancer among Women in three Metropolitan Cities of Southwestern States of Nigeria}

\section{OMOYAJOWO, KO ${ }^{1,2}$, OGUNYEBI, AL ${ }^{2}$, ADENEKAN, OA ${ }^{1}$, BAKARE, TI $^{3,4}$, OMOYAJOWO, BO $^{5}$, ODIPE, OE $^{6}$, SAMUEL, IA ${ }^{7}$}

${ }^{1}$ Department of Science Policy and Innovation Studies, National Centre for Technology Management, Lagos, Nigeria

${ }^{2}$ Department of Cell Biology and Genetics, University of Lagos, Nigeria

${ }^{3}$ African Institute for Science Policy and Innovation, Obafemi Awolowo University, Ile-Ife, Nigeria

${ }^{4}$ Global Health Mentorships, Copenhagen, Denmark

${ }^{5}$ Department of Chemistry, Ekiti State University, Ado-Ekiti

${ }^{6}$ Department of Environmental and Occupational Health Science, School of Public Health, University of Medical Sciences, Ondo

${ }^{7}$ Department of Environmental Health Science, Kwara State University, Malete

*Corresponding Author Email: tolu.bakare.tb@gmail.com

\begin{abstract}
This study evaluated the public awareness level on the toxicological nature of talcum powder and the perceived risk of ovarian cancer among women in order to design effective interventions that will ultimately improve public health among all women in Nigeria. A risk perception survey was developed to capture the public awareness level about talcum powder as an emerging contaminant and risk of ovarian cancer, inquiring whether risk is viewed positively or negatively and the extent of worry or concern. A total of 300 questionnaires were administered and returned, analyzed and interpreted for policy decision making. Each questionnaire contains mostly Likert type questions featuring a set of risks with fixed response alternatives. Basic descriptive statistics was considered for explanatory variables: age, educational attainment and generalized risk sensitivity. Majority of respondents use talcum powder for different purposes. $28 \%$ of respondents use talcum powder for genital hygiene, out of which $42.86 \%$ use this cosmetic product on a daily basis. Poor level of awareness was generally observed as most respondents do not know whether talcum powder could be considered a potential risk factor for ovarian cancer. Majority (66.43\%) were very concerned about the risk of ovarian cancer but perceived less risk for ovarian cancer when asked to compare risk with their respective age groups. Notably, poor level of awareness about the toxicological nature of talc and the relatively high level of perceived risk of developing ovarian cancer due to previous talc exposure was evident among respondents in our study.
\end{abstract}

Keywords: Risk Perception, Talcum powder, Ovarian Cancer, Advocacy, Nigerian Women 


\section{INTRODUCTION}

Talcum powder (or Talc) has long been considered a potential risk factor for lung, ovarian, stomach and uterine cancers because of the presence of asbestos, a proven toxicant, however, information about its toxicological nature is not widely known. Talcum powder is made from talc, a naturally occurring clay mineral made up of magnesium, silicon and oxygen, (US-NLM, 2021) which absorbs moisture, oils and odor when finely ground and reduces friction and which interestingly produce an astringent effect on the human skin (Robert, 2012, McDonald et al, 2019). Talcum powder indeed has many benefits. About $40 \%$ of women worldwide are said to regularly use talcum powder, which can be found in many baby powders, foot powders, medicated powders, cosmetics and intimate hygiene products (Miller, 2021). In the cosmetic industry, it is used as an abrasive, absorbent, anticaking agent, bulking agent, opacifying agent, skin protectant, and slip modifier (PCPC, 2010; Gottschalck and Breslawec, 2012). Talc is reported to be used in face powders at 100\%, baby powders at 99\%, foot powders and sprays at up to $97 \%$, in aerosol makeup bases at up to $35 \%$, and in aerosol deodorants at up to $30 \%$ (PCPC, 2012). It has been reported that it has the potential to soothe dry skin and treat Eczema, thicken women's eyelashes for facial make-up, prevent shoes from smelling when sprinkled on the foots and that it makes an excellent body deodorant and a good pest-repellant (USGS, 2000).

In spite of these benefits, experts have reasoned that talcum powder applied directly to the genital area or on sanitary napkins, diaphragms or condoms may be cancer-causing to the ovaries (Muanya, 2019). In a recent report, women who have used talcum powder on a weekly basis may face a 33\% increase in their risk of developing ovarian cancer, and women who have used talcum powder on a daily basis are thought to face a $41 \%$ increase in risk for ovarian cancer (Onderlaw, 2020). A recent study reported that talc could cause toxicosis in pregnant women (Pennycuff et al., 2018), and that even without asbestos and other known toxic contaminants, may elicit inflammation and contribute to lung disease (Sato et al., 2020). Over 20,000 individual lawsuits on talc products have been filed across the United States (Miller and Zois, 2021) and massive awareness about compensation funds to affected individuals and families is currently being sponsored on some popular American Television stations.

Since the 1960s, there has been speculations that talcum powder's use may induce ovarian cancer growth, however, the first epidemiological study on talc powder use in the female genital 
area and its possible association with ovarian cancer was first reported in 1982 (Cramer et al., 2016). Another case-control research conducted by the African American Cancer Epidemiology study suggests that African American women are more prone to the risks of ovarian cancer due to their frequent use of talc-based powder (Schildkraut et al., 2016; Cohen, 2016). However, there have been recent studies with skeptical views (Trabert, 2016; O'Brien et al., 2020; Neill, 2012), stating that previous studies are prone to recall bias which may have been as a result of the media projection of the talc lawsuits at the time of the study. According to O'Brien et al., (2020), the conclusion of the relationship between talc-based powder and ovarian cancer is based on observational and case-control research which is not sufficient enough to establish a significant relationship. It was advocated that cohort studies are required to confirm such claims. With the recent advances and diverse views on the study of the relationship between talc-based powders and the risk of ovarian cancer, it was clear that there may be skepticism about the relationship between the use of talcum powder and the risk factor of ovarian cancer (Wentzensen and Wacholder, 2014).

Ovarian cancer accounts for about $3.6 \%$ of diagnosed cancer forms in Nigeria. Being the sixth prevalent cancer among Nigerian women, it remains one of the leading causes of genital cancer with an incidence of about 3.1 per 100,000 women (Okunowo and Adaramoye, 2018). It is perhaps the most lethal gynecologic malignancy and potential risk factors are enormous; It includes asbestos exposure, smoking, heredity, endometriosis, pelvic inflammatory disease, obesity among others, all of which are closely linked to the risk of uterine cancer (Omoyajowo et al., 2018; Rajput et al., 2019). Early diagnosis gives about a 93\% chance of survival for patients (Freij, 2018). Unfortunately, the absence of effective screening strategy and non-specific symptoms accompanied by ovarian cancer makes the management of ovarian cancer difficult. Hence, it has become imperative to continuously improve public knowledge on the potential risk factors associated with ovarian cancer (Freij, 2018). Increasing public knowledge on the potential risk factors of ovarian cancer and its possible management strategies may promote early presentations and medical checks by patients and hence, reducing the odds of morbidity and mortality due to cancer proliferation (Okunowo and Adaramoye, 2018; Omoyajowo et al., 2018). 
Up to now, hardly any research has explored public knowledge on the toxicological impact of talc particles and risk perception studies vis-à-vis development of ovarian cancer among women especially on the premise that talc is a proven carcinogen. This may be due to low level of public sensitization on the risks and management of ovarian cancer (as compared to most common cancer type in women such as breast and cervical cancer). It has been demonstrated that education and enlightenment of the public by health professionals increases knowledge of the risk factors associated with ovarian cancer (Okunowo and Adaramoye, 2018).

Risk perception or perceived susceptibility is regarded as an individual's subjective perception of the likelihood of developing a disease (Rajput et al, 2019). The Health Belief model states that personal beliefs about a disease influence health behaviour and interventions that change risk perceptions subsequently change health behaviors (Ferrer and Klein, 2015; Rajput et al., 2019). In health decision-making, people are expected to navigate choices involving weighing risk for consequences with benefits of action (Ferrer and Klein, 2015). For instance, human behaviors contributing to the initiation and progression of diseases are often pleasurable (e.g., smoking or overeating).

Taken together, studies have considered the use of talcum powder for genital hygiene as a potential risk factor for ovarian cancer (Muscat and Huncharek, 2008, Muanya, 2019) but its toxicological nature may not be widely known. Developed countries particularly the European Union have banned talcum powder (EU, 2020) but it is still widely used in Nigerian households and cosmetic industry. More so, we believe this present study is the first work that seeks "Public knowledge on the relationship between the use of talc and the risk of ovarian cancer especially among Nigerian women". Hence, the main thrust of this study is to evaluate the awareness on the toxicological impact and the risk of using talcum powder as a factor for ovarian cancer in three metropolitan cities of Southwestern states in Nigeria. This paper is organized into four parts. Section 1 introduces the subject of the study; Section 2 presents the methodology used for the study. Section 3 presents the results and discussion of the study. The final section concludes and makes some insightful recommendations. 


\section{MATERIALS AND METHODS}

\section{Description of Study Locations}

This study was conducted in three metropolitan cities of Southwestern states in Nigeria. These cities were Ikeja, Akure and Ado-Ekiti. Ikeja is the capital of Lagos and Lagos is the commercial nerve of Nigeria, a megacity that offers hope and equal opportunities for both men and women of diverse tribes and origins due to the presence of several industries and transport systems. Akure is the capital of Ondo state; an agricultural trade centre for cocoa, cassava, corn (maize). Ado-Ekiti is the capital of Ekiti State, a state that is unique for her beautiful landscape, with several rugged hills, mountains and a mix of tropical forest (south) and Savannah (north), which ultimately supports arable farming and livestock rearing. In terms of population, Lagos, Ondo and Ekiti States have about 9 million, 3.4 million and 2.3 million respectively with each State having almost equal gender distribution (NBS, 2006).

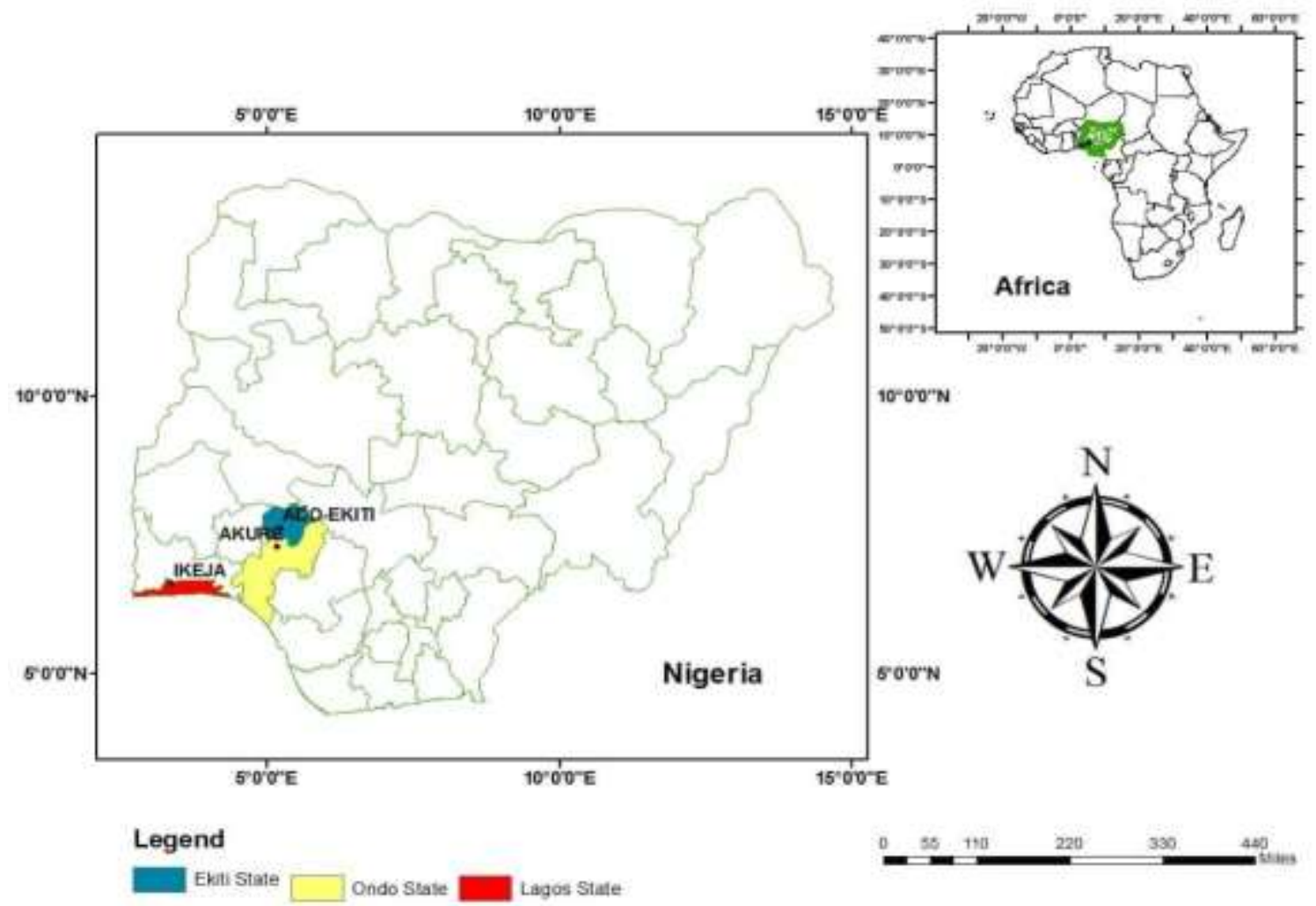

Fig. 1: Map showing study areas 


\section{Research Design \& Data Collection}

A structured, self-administered questionnaire comprising 16 questions delivered to participants via both face-to-face ('drop and collect' method) and online interviews was used to assess the knowledge about talcum powder' s use vis-à-vis beliefs and perceived risk of developing ovarian cancer. Questionnaire was developed in English and took on average five minutes to complete. For questionnaires administered online, we created online survey using Google form and shared among our research survey assistants in each State and were properly guided on how to administer this survey version. The psychometric model of risk perception was used, a method explicitly described by Gaskell et al., (2017). Basically, respondents were asked to assess a number of potential risks on a five point scale of worry or concern. Nonetheless, all respondents were asked the same question and offered the same set of response alternatives, thereby potentially eliminating the interviewer's bias. Respondents were generally asked whether they had awareness about possible development of ovarian cancer through previous talcum powder exposure, whether the risk is viewed positively or negatively and the extent of worry or concern. Specifically, "Vulnerability" was measured by asking how likely the respondents thought they would get ovarian cancer in the next year (scale very unlikely (1) to very likely (5)). To measure response efficacy for ovarian cancer vis-à-vis talcum powder, it was asked if discontinuing the use of talcum powder would be considered a preventative measure (Certainly not, most certainly, perhaps not, perhaps yes, probably not, and probably yes). The demographic information asked for in the questionnaire included age, level of education and marital status. Recruitment (and interviews) lasted for five months (within early October 2020 - February 2021). Since the 300 interviews generated broadly similar responses, it was adjudged that an adequate sample size had been reached (Guest et al., 2006). Participants signed consent forms before interviews and respondents aged 18-75 years were considered eligible to participate. They were informed that participation was voluntary and confidentiality and anonymity of responses were guaranteed. Recorded interviews were transcribed verbatim and checked for accuracy. Data analysis was done on Microsoft Excel 2010 however, there were some inherent limitations, very few people turn up for the recruitment and the study does not ask for participants' occupational history, lifestyle (alcohol consumption, smoking etc.), health related characteristics, religion and asbestos exposure to each job done within the last 6-12 months. 


\section{RESULTS AND DISCUSSION}

In this study, a total of 300 valid respondents were generated from various geographical areas (Fig.1), most of which were between 26-35 years (35\%), only $2 \%$ were divorced while single and married women had almost a fair equal proportion (49.3\% and $49 \%$ respectively). With reference to respondents' educational attainment, the majority $(61 \%)$ had Bachelor degree or equivalent while very few (3\%) had $\mathrm{PhD}$. (Table.1)

Table 1: Socio-demographic Information of Respondents

\begin{tabular}{|c|c|c|c|c|}
\hline \multicolumn{2}{|c|}{$\begin{array}{l}\text { Respondents } \\
(n=300)\end{array}$} & \multirow{2}{*}{\begin{tabular}{|l} 
Sub-categories \\
$18-25$ \\
\end{tabular}} & \multirow{2}{*}{$\begin{array}{l}\text { Frequency } \\
94\end{array}$} & \multirow{2}{*}{$\begin{array}{l}\begin{array}{l}\text { Percentage } \\
(\%)\end{array} \\
31.3\end{array}$} \\
\hline i. & Age (years) & & & \\
\hline & & $26-35$ & 105 & 35 \\
\hline & & $36-35$ & 67 & 22.3 \\
\hline & & $46-55$ & 28 & 9.3 \\
\hline & & $56-65$ & 4 & 1.3 \\
\hline & & $>65$ & 2 & 0.7 \\
\hline \multirow[t]{3}{*}{ ii. } & $\begin{array}{l}\text { Marital } \\
\text { Status }\end{array}$ & Divorced & 5 & 2 \\
\hline & & Married & 148 & 49 \\
\hline & & Single & 147 & 49 \\
\hline \multirow[t]{5}{*}{ ii. } & Education & $\begin{array}{l}\text { Bachelors or } \\
\text { equivalent }\end{array}$ & 182 & 61 \\
\hline & & Masters & 64 & 21 \\
\hline & & OND/NCE & 34 & 11 \\
\hline & & $\mathrm{PhD}$ & 9 & 3 \\
\hline & & $\begin{array}{l}\text { Primary School } \\
\text { leaving Certificate }\end{array}$ & 11 & 4 \\
\hline
\end{tabular}

$\mathrm{OND} / \mathrm{NCE}=$ Post-High School National Diploma or Certificate

Source: Field Survey, 2021 
Majority of the respondents $(77 \%)$ claimed that they make use of talcum powder (either as beauty make-up material, for genital hygiene or for soothing their skin) while only few (23\%) indicated that they do not make use of it (Figure 2).

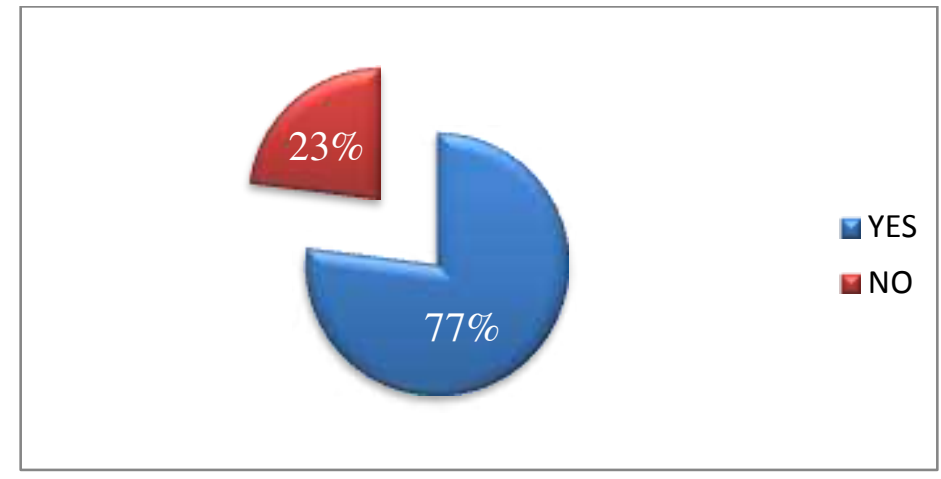

Figure 2: Chart of respondents that uses Talcum powder $(n=300)$

Source: Field Survey, 2021

Among respondents that use talcum powder ( $\mathrm{n}=233$ ), about $42 \%$ use talcum powder on a daily basis, $20 \%$ use it twice daily, $13.7 \%$ use weekly and only $2 \%$ use it once in a while (Fig.3).

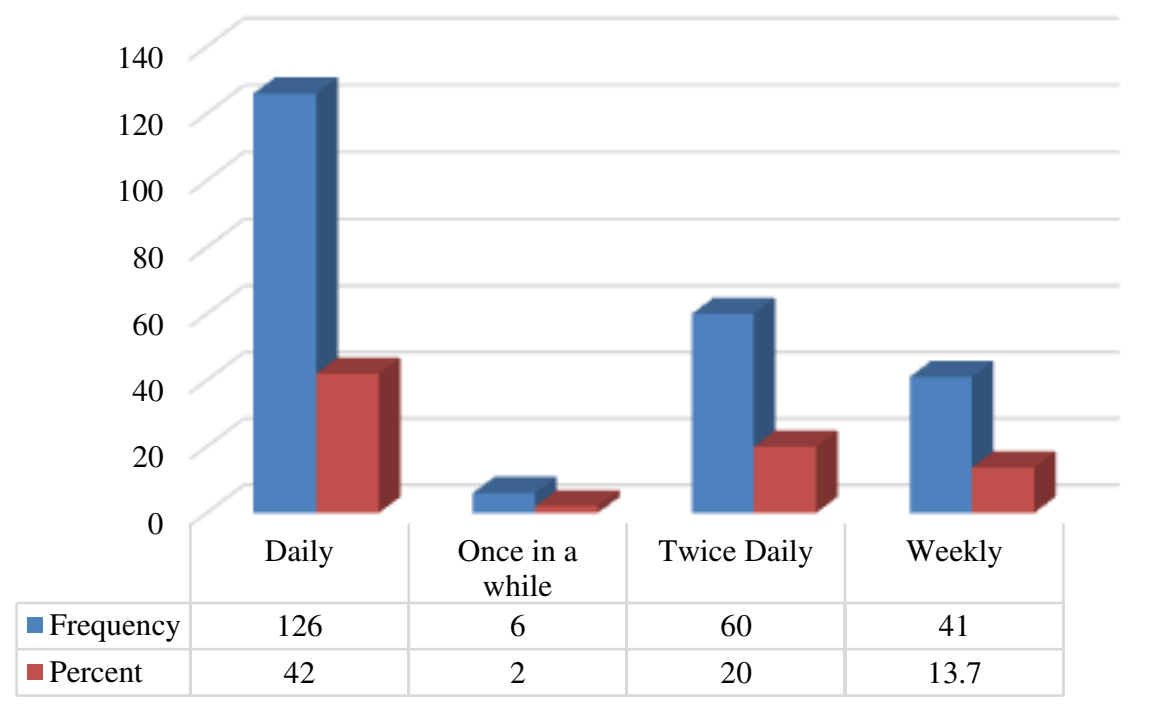

Figure 3: Chart showing how Respondents often use Talcum powder $(\mathrm{n}=233)$ Source: Field Survey, 2021 
Some of the respondents (34\%) indicated that talcum powder is mostly applied to soothe their dry skin and treat eczema, while others (28\%) particularly used talcum powder for genital hygiene (Figure 4). However, two anonymous respondents further averred that "The use of Talcum powder for genital hygiene is a common practice among female sex workers in Nigeria"

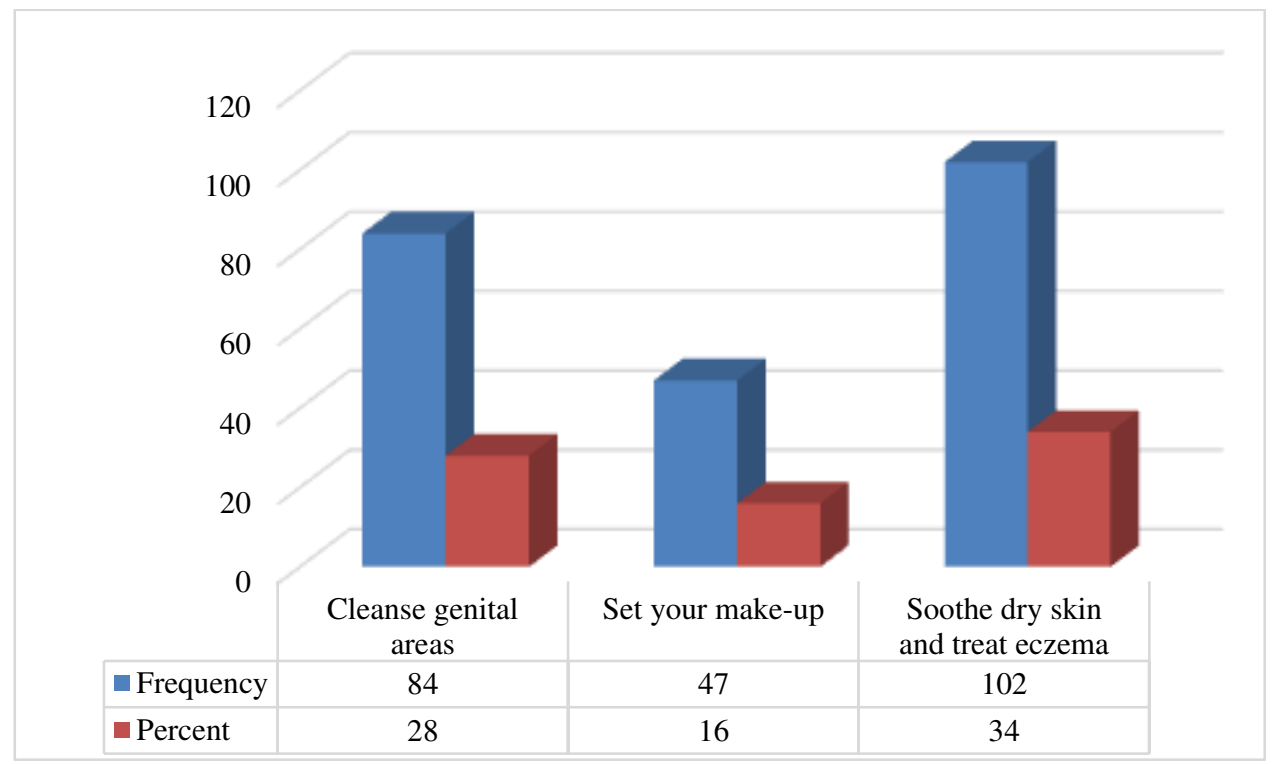

Figure 4: Chart showing the various ways that Respondents use Talcum powder $(n=233)$ Source: Field Survey, 2021

Less than half of the proportion of respondents (42.86\%) who earlier claimed using talcum powder for genital hygiene use it on a daily basis, while $25 \%, 16.67 \%, 10.71 \%$ and $4.76 \%$ of respondents claimed using it twice daily, bi-weekly, weekly and monthly respectively (Figure 5). 


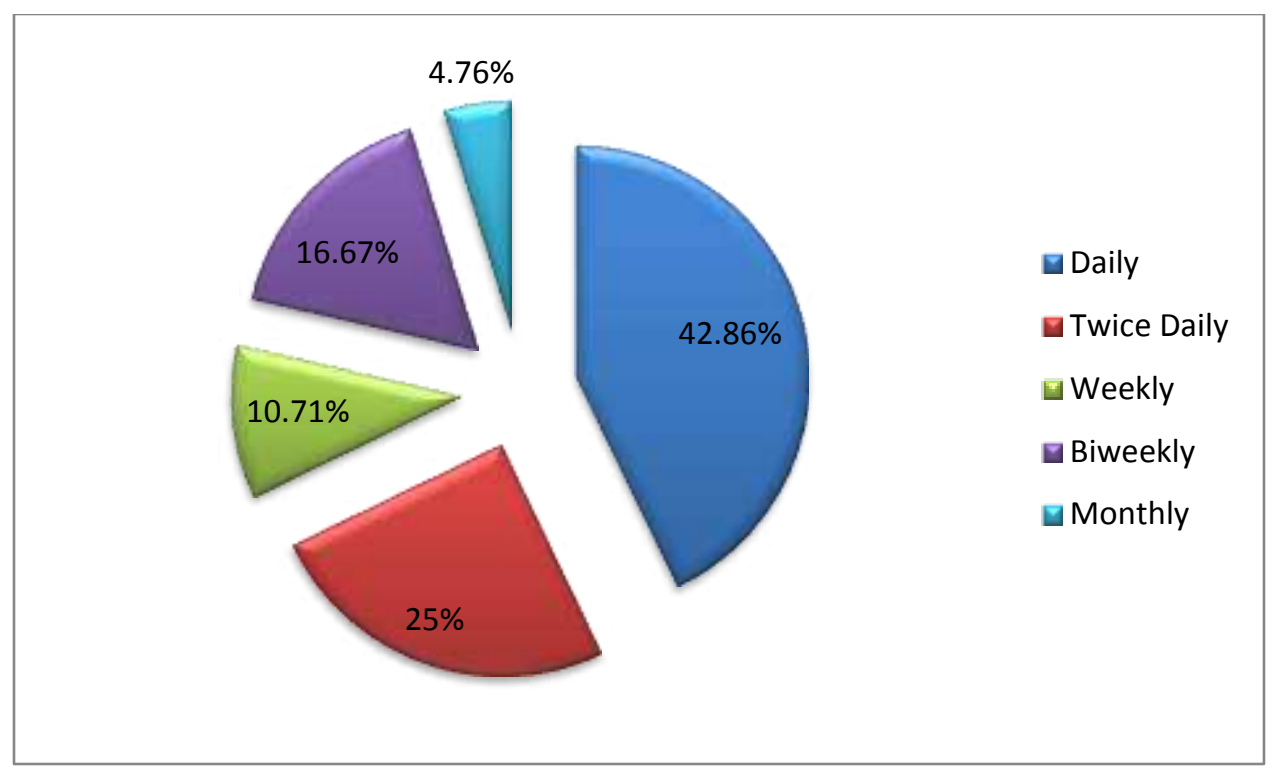

Figure 5: Chart showing how often Respondents use Talcum powder for Genital hygiene (i.e. to cleanse female genital areas, $n=84$ )

Source: Field Survey, 2021

Majority of respondents (83\%) were not really aware whether talcum powder contains asbestos, a possible carcinogen to the women's ovaries while only a few (17\%) claimed awareness on this subject and more so, their source(s) of information were mostly family and/or friends (32.65\%) and the internet (28.57\%). Majority (71.3\%) expressed willingness in getting a talcum compensation fund if they or their family members were diagnosed of ovarian cancer, only few (5\%) were diagnosed of ovarian cancer while the period of diagnosis followed this order: less than 1 year $(50 \%)>1-3$ years $(42.86 \%)>4$ years and above $(7.14 \%)$ as shown in Table 2 . However, only $2 \%$ had a family history of ovarian cancer; $12 \%$ were not sure but $86 \%$ claimed not having family history of ovarian cancer. 
Table 2: Level of awareness on talcum powder, information sources an $d$ other information vis-à-vis ovarian cancer diagnosis

\begin{tabular}{|c|c|c|c|}
\hline Variables & Categories & Frequency & Percentage (\%) \\
\hline \multirow{2}{*}{$\begin{array}{l}\text { Awareness on whether talcum powder } \\
\text { contains asbestos, a carcinogen } \\
(\mathrm{n}=300)\end{array}$} & Yes & 51 & 17 \\
\hline & No & 249 & 83 \\
\hline \multirow{6}{*}{$\begin{array}{l}\text { Source of information on awareness } \\
\text { of Talc powder being a carcinogen } \\
(\mathrm{n}=49)\end{array}$} & Family and/or Friends & 16 & 32.65 \\
\hline & Internet & 14 & 28.57 \\
\hline & Newspapers/Magazines & 5 & 10.20 \\
\hline & Radio & 2 & 4.08 \\
\hline & Television & 3 & 6.12 \\
\hline & Medical Professionals & 9 & 18.37 \\
\hline \multirow{3}{*}{$\begin{array}{l}\text { Willingness to get talcum powder } \\
\text { compensation funds if respondents or } \\
\text { their family relatives were diagnosed } \\
\text { of ovarian cancer }(n=300)\end{array}$} & Yes & 214 & 71.3 \\
\hline & No & 25 & 8.3 \\
\hline & Not Sure & 61 & 20.3 \\
\hline \multirow{2}{*}{$\begin{array}{l}\text { Diagnosed of ovarian cancer before? } \\
(\mathrm{n}=300)\end{array}$} & Yes & 15 & 5 \\
\hline & No & 285 & 95 \\
\hline \multirow{3}{*}{$\begin{array}{l}\text { Period which ovarian cancer was } \\
\text { diagnosed }(n=14)\end{array}$} & $<1$ year & 7 & 50 \\
\hline & 1-3 Years & 6 & 42.86 \\
\hline & 4years and above & 1 & 7.14 \\
\hline \multirow{3}{*}{$\begin{array}{l}\text { Family history of ovarian cancer } \\
(\mathrm{n}=300)\end{array}$} & Yes & 6 & 2 \\
\hline & No & 258 & 86 \\
\hline & Not Sure & 36 & 12 \\
\hline
\end{tabular}

Source: Field Survey, 2021 
Respondents generally considered ovarian cancer as a serious disease and expressed varying levels of concerns for the risk of ovarian cancer: $66.43 \%$ were "very concerned", $16.43 \%$ were "concerned", 7.69\% were "slightly concerned", 5.59\% were "not concerned" about the risk of developing ovarian cancer (Table 3). Additionally; 37.45\% perceived they were "likely", 12.73\% "very likely", $12.36 \%$ were neutral, $21.81 \%$ were unlikely and $15.64 \%$ were "Very unlikely" at the risk of developing ovarian cancer on the basis of previous talc exposure . However, their perception of risk when compared to other women in their age group differs. The likelihood of developing ovarian cancer due to previous talc exposure in comparison with other women in their age group thus followed this order: Very unlikely $(43.36 \%)>$ unlikely $(20.97 \%)>$ neutral $(16.78 \%)>$ very likely $(12.28 \%)>$ likely $(6.64 \%)$.

When respondents were asked on "What they thought about discontinuing the use of talcum powder as a preventive measure", their responses assumed this order: Probably Yes (35.67\%) > Perhaps Yes (20.33) > Probably Not (15.33\%)> Most Certainly (10.67\%) > Certainly Not (6\%). Hence, the vast majority of our respondents agreed that "Discontinuing talcum powder's use especially on genital areas will help to reduce the possible risk of ovarian cancer growth". 
Table 3: Perceived risk of ovarian cancer among respondents

\begin{tabular}{|c|c|c|c|}
\hline Variables & Categories & $\mathbf{f}$ & $\%$ \\
\hline \multirow{5}{*}{$\begin{array}{l}\text { *How would you feel if you develop ovarian cancer in the } \\
\text { coming year? } \\
(\mathrm{n}=286)\end{array}$} & Concerned & 47 & 16.43 \\
\hline & $\begin{array}{l}\text { Not at all } \\
\text { concerned }\end{array}$ & 11 & 3.85 \\
\hline & Not concerned & 16 & 5.59 \\
\hline & $\begin{array}{l}\text { Slightly } \\
\text { concerned }\end{array}$ & 22 & 7.69 \\
\hline & Very concerned & 190 & 66.43 \\
\hline \multirow{5}{*}{$\begin{array}{l}\text { *What is the likelihood of developing ovarian cancer in the } \\
\text { next one year on the basis of your previous exposure to } \\
\text { talcum powder? } \\
(\mathrm{n}=275)\end{array}$} & Likely & 103 & 37.45 \\
\hline & Neutral & 34 & 12.36 \\
\hline & Unlikely & 60 & 21.81 \\
\hline & Very Likely & 35 & 12.73 \\
\hline & Very Unlikely & 43 & 15.64 \\
\hline \multirow{5}{*}{$\begin{array}{l}* * \text { What is the likelihood of developing ovarian cancer due to } \\
\text { your previous talc exposure and in comparison to other } \\
\text { women of your age in the next one year? } \\
(\mathrm{n}=286)\end{array}$} & Likely & 19 & 6.64 \\
\hline & Neutral & 48 & 16.78 \\
\hline & Unlikely & 60 & 20.97 \\
\hline & Very Likely & 35 & 12.24 \\
\hline & Very Unlikely & 124 & 43.36 \\
\hline \multirow{6}{*}{$\begin{array}{l}\text { Do you think that discontinuing talc powder use on genital } \\
\text { areas will help to prevent possible ovarian cancer growth? } \\
* * * \\
(\mathrm{n}=300)\end{array}$} & Certainly Not & 18 & 6 \\
\hline & Most Certainly & 32 & 10.67 \\
\hline & Perhaps Not & 36 & 12 \\
\hline & Perhaps Yes & 61 & 20.33 \\
\hline & Probably Not & 46 & 15.33 \\
\hline & Probably Yes & 107 & 35.67 \\
\hline
\end{tabular}

*Perceived Risk Vulnerability, **Comparative risk perception, *** Response efficacy, $\mathrm{f}=$ frequency, \%=Percentage score

Source: Field Survey, 2021

The analysis of socio-demographic information may help us understand whether social identity is causing people to act in specific ways or to understand if specific factors (or actions) may cause people to adopt a certain identity (Abdelal et al., 2009). In this study, we had a fair sample of single and married women with almost equal proportion (49.3\% and 49\% respectively) and majority (61\%) had Bachelor degree or equivalent (Table 1). A possible explanation for this outcome is that people who are educated may have a better knowledge on issues of public health importance. 
Our findings have clearly revealed that a lot of Nigerian women sampled (77\%) use talcum powder for various reasons or purposes, $42 \%$ of which use talcum on a daily basis perhaps because of the need to relieve their body or skin from relatively harsh environmental conditions or warning skin irritation. It is quite apposite to believe that the human body skin may react to harsh hot weather and the use of talcum powder may often be relied upon especially to soothe skin or when necessary. However, it was also obvious that some Nigerian women use talcum powder for genital hygiene. Talc, is often used for genital hygiene purposes and it is a possible risk factor for ovarian cancer (Sato et al., 2020). The statement that the" Use of talcum powder for genital hygiene is a common practice among female sex workers in Nigeria" being asserted by two of our anonymous respondents might be valid. Cramer et al., (2016) described "Genital talc use" as regular and direct application of talc powder to the genital/ rectal area on sanitary napkins, tampons, underwear and other intimate products for genital hygiene. Strong advocacy on the abolishment of genital talc use and massive awareness on the toxicological nature of talcum powder would definitely be required throughout the nation.

Improving public knowledge on new and emerging public health issues as well as their preventive health measures is a reliable pathway to ensuring a sustainable healthy environment. With a good public health program, the public can literarily access relevant and timely health information and can live healthier for a longer time. Inspite having a good sample of respondents that are educated (Table 1), yet this study observed a poor level of awareness about the toxicological nature of talcum powder. This implies that being educated may not necessarily translate to having adequate knowledge about public health issues. In another breathe of reasoning; the poor level of awareness on this subject may be due to inaccessibility of public health information. Studies have demonstrated that talc particles can travel through genital areas to the ovaries and stay for a long period of time, causing inflammation and subsequently resulting to ovarian cancer due to the presence of asbestos, a proven carcinogen in talc (Cramer et al., 2016; O'Brien et al., 2020). Improving public understanding on this subject would greatly help to reduce public exposure to the toxicological impact of talcum powder. Only a few (17\%) had knowledge on this subject: Family and friends as well as the "Internet" were mostly their sources of information. Poor knowledge about diseases and their risk factors especially among women has been underscored as a major setback in the general management of diseases (Lockwood-Rayermann, 2009). Hence, the need to raise the awareness of ovarian cancer and 
educate women about its symptoms and possible risk factors to encourage early presentation and detection of the disease is very critical (Brain et al., 2014). We believe bridging the knowledge gap on this critical subject is fundamentally a collective endeavor that would require active engagement of the community, policy makers, academia, and civil society actors. Nonetheless, advocacy programs and discussions on public health issues should be strategically communicated in a culturally and emotionally appropriate context.

Indeed, the public may explore different information sources (e.g. social media, the internet, government agencies, radio/television programs etc.) to learn about "new health risks" and "new health and safety guidelines", the outcome of which could help in promoting healthy behaviours. However, regardless of where the public are sourcing for information on public health issues, it is very crucial to understand that the central idea about public health awareness is to empower people through sharing knowledge on the possible measures to prevent diseases in order to realize their health potential. This is because "Prevention could be far more effective and less expensive than the cure". Based on the findings in this study, "Word of mouth" through family and friends and the "Internet" were the mostly cited information sources among respondents who had knowledge of the toxicological nature of talc. The foregoing statement logically implies that in order to achieve significant strides towards inclusive dissemination of public health information, other information sources should be well utilized or integrated. By and large, it is logical to adjudge that lack of public awareness on the toxicological nature of talcum powder especially when used for genital hygiene may significantly increase the risk of ovarian cancer.

Generally, the respondents in this study were highly concerned about the risk of developing ovarian cancer due to their previous exposure to talc powder. This finding is in agreement with the earlier study which expounded that there is an increased risk of ovarian cancer in women who used talc on their perineum over a long period of time (Merritt et al., 2008). Not surprisingly, the vast majority of respondents indicated the likelihood of developing ovarian cancer due to their previous exposure to talc. The general high usage of talc in this current study may explain why they perceived risk of developing ovarian cancer as high.

A good number of women in our study expressed that they are not likely to develop ovarian cancer in the next one year compared to women of their age group. A possible explanation for 
this outcome could be linked to individual's subjective belief and conviction. However, most of the women were of the opinion that discontinuing the usage of talc-based powder on the genital areas will possibly mitigate the risk of developing ovarian cancer. Understanding the need to eradicate all possible health risks is considered a preventive rationale; this component could interactively influence health protective behaviors (Ferrer and Klein, 2015).

Majority of the respondents were willing to file lawsuits against manufacturers of talcum powder in order to claim product liability grants if they or their loved ones had ovarian cancer. Their willingness to file lawsuits against manufacturers may be hinged on two major standpoints: First, the treatment or available management option for ovarian cancer is for the most part expensive, which may cost them their entire life's savings and the latter, on the premise that producers or profiteers of talcum powder should be held accountable for their misfortune.

\section{CONCLUSION}

This study have observed a very low level of knowledge or awareness about the toxicological nature of talc as well as a relatively high level of perceived risk of developing ovarian cancer among respondents due to previous talc exposure. Importantly, this study advocates that women should be properly sensitized and/or well-informed on the toxicological nature of talc, especially its use for genital hygiene should be abolished. However, the use of safe alternative body powders (e.g. corn starch powder) should be encouraged. Furthermore, government and civil society actors should encourage victims of talc-induced ovarian cancer to pursue a product liability claim against manufacturers and large distribution firms of talc products.

\section{Acknowledgements}

We collectively extend our sincere gratitude to all participants and survey administrators for their voluntary contribution to the success of this study. In the same vein, we thank Dr. Olusola Awoyemi and Mr. Mela Danjin for their insightful comments on the previous draft.

\section{REFERENCES}

Abdelal, R; Herrerra, YM; Johnston, AI; McDermott, R. (2009). Measuring Identity: A Guide for Social Scientists, Cambridge University Press. New York 
Brain, KE; Smits, S; Simon, AE; Forbes, LJ; Roberts, C; Robbé, IJ; Steward, J; White, C; Neal, RD; Hanson, J., \& ICBP Module 2 Working Group (2014). Ovarian cancer symptom awareness and anticipated delayed presentation in a population sample. BMC cancer 14:171.

Cohen, R (2016). Talc linked to ovarian cancer risk in African-American women. Reuters Health News. June 6, 2016. https://www.reuters.com/article/us-health-talc-ovariancancer/talc-linked-to-ovarian-cancer-risk-in-african-american-women-idUSKCNOYO2T7

Cramer, DW; Vitonis, AF; Terry, KL; Welch, WR; Titus, LJ (2016). The association between Talc Use and Ovarian Cancer: A Retrospective Case-Control Study in Two US States Epidemiology 27: 334-346

European Union (2020). Restricted Substances: Annex III, Regulation 1223/2009/EC on Cosmetic Products, as amended by Regulation (EU) 2020/1683, 13 November 2020

Ferrer, R; Klein, W.M. (2015). Risk perceptions and health behaviours. Curr Opin. Psychol 5:85-89

Freij M; Al Qadire M; Khadra M; ALBashtawy M; Tuqan W; Al Faqih M; Innabi A; Batiha AM, Alhalaiqa F, Abd El-Razek A (2018). Awareness and Knowledge of Ovarian Cancer symptoms and Risk factors: A Survey of Jordanian women. Clin. Nurs. Res. 27(7):826-840.

Gaskell, G; Hohl, K; Gerber, M. (2017). Do closed survey questions overestimate public perceptions of food risks? J. Risk Res. 20:1038-1052

Gottschalck TE; Breslawec, HP (2012) International Cosmetic Ingredient Dictionary and Handbook. 14 ed. Washington, DC: Personal Care Products Council

Guest, G., Bunce, A; Johnson L (2006). How many interviews are enough? An experiment with data saturation and variability. Field Methods, 18(1), 59-82.

Lockwood-Rayermann S; Donovan HS; Rambo D; Kuo CW. (2009) Women's awareness of ovarian cancer risks and symptoms: analysis of responses to an online survey shows that women ages 40 and older are not well informed. Am. J. Nurs. 1:36-46.

McDonald, SA; Fan Y; Rogers RA; Godleski, JJ. (2019). Magnesium/silicon atomic weight percent ratio standards for the tissue identification of talc by scanning electron microscopy and energy dispersive X-ray analysis. Ultrastruct pathol. 43(6):248-6

Merritt MA; Green AC; Nagle CM; Webb PM (2008). Talcum powder, chronic pelvic inflammation and NSAIDs in relation to risk of epithelial ovarian cancer. Int $J$ Cancer. 122(1):170-176. 
Miller and Zois (2021). Talcum Powder Lawsuit Update. Retrieved from https://www.millerandzois.com/talcum-powder-lawsuits.html . June 29, 2021.

Miller, E. (2021). Talcum powder and Ovarian cancer. Retrieved from https://www.drugwatch.com/talcum-powder/ovarian-cancer/ on Feb 12, 2021

Muanya, C (2019). Nigeria: Talcum Powder May Cause Cancer, Experts Warn. Retrieved The Guardian 22nd March 2019 https://allafrica.com/stories/201903220062.html

Muscat, JE; Huncharek, MS (2008). Perineal talc use and ovarian cancer: a critical review. Eur. J. Cancer Prev. 17(2), 139-146.

NBS -National Bureau of Statistics (2006). 2006 National Population Census/Federal Republic of Nigeria. Retrieved 19 March 2021 from the National Bureau of Statistics http://www.nigerianstat.gov.ng/nbsapps/Connections/Pop2006.pdf

Neill, AS; Nagle, CM; Spurdle, AB; Webb PM. (2012). Use of talcum powder and endometrial cancer risk. CCC 23(3):513-9.

O'Brien, KM; Tworoger, SS; Harris, HR; Anderson, GL; Weinberg, CR; Trabert, B; Kaunitz, AM; D'Aloisio, AA., Sandler, DP; Wentzensen, N (2020). Association of Powder Use in the Genital Area with Risk of Ovarian Cancer. JAMA, 323(1), 49-59.

Okunowo AA; Adaramoye VO (2018) Women's knowledge on ovarian cancer symptoms and risk factors in Nigeria: an institutional-based study. JEGH 8(1-2):34.

Omoyajowo, KO; Asaolu, MF; Adenekan, OA; Ogidan, JA; Olaniyan, K. (2018). Investigation of Plasma Electrolyte levels in selected uterine cancer Patients. JRRS 4: 63-69

OnderLaw, LLC. (2021). Talcum Powder Cancer Lawsuit Center. Retrieved from http://www.talcumpowdercancerlawsuitcenter.com on Feb. 12 $2^{\text {th }}, 2021$

Pennycuff, J.F; Davenport, A; Ellis, J; Patberg, E; Cwiak, C (2018). Talcum Powder Toxicosis in Pregnancy Am J Perinatol Rep 8:e384-e386.

Personal Care Products Council (PCPC) (2010). Updated Concentration of Use Talc. In: Cosmetic Ingredient Review 2012. Talc as Used in Cosmetics. Retrieved from https://studylib.net/doc/8672931/scientific-literature-review-talc-as-used-in-cosmetics-au. On January 25, 2021

Personal Care Products Councils (PCPC) (2012). In: Cosmetic Ingredient Review 2012. Scientific Literature Review: Talc as Used in Cosmetics. Retrieved from 
https://studylib.net/doc/8672931/scientific-literature-review-talc-as-used-in-cosmetics-au. on January 25, 2021.

Rajput, Z; Hering, KG; Kraus, T; Tannapfel, A; Sonnenschein, G; Centmayer, A; Radon, K, Nowak, D; Weinmann, T. (2019). Investigating the association between occupational exposure to asbestos and ovarian carcinoma: results from a pilot study in Germany. BMC Public Health 19:1341

Robert, LV (2012) U.S. Geological Survey, Mineral Commodity Summaries, January 2012.

Sato, E; McDonald, SA; Fan, Y; Peterson, S; Brain, JD; Godleski, JJ. (2020). Analysis of particles from hamster lungs following pulmonary talc exposures: implications for pathogenicity. Part. Fibre Toxicol. 17:20

Schildkraut, JM; Abbott SE; Alberg AJ; Bandera EV; Barnholtz-Sloan JS; Bondy ML; Cote ML, Funkhouser E; Peres LC; Peters ES; Schwartz AG (2016). Association between body powder use and ovarian cancer: the African American Cancer Epidemiology Study (AACES). Cancer Epidemiol. Biomark. Prev. 25(10):1411-1417.

Trabert, B (2016). Body powder and ovarian cancer risk-what is the role of recall bias? Cancer Epidemiol. Biomark. Prev. 25(10):1369.

U.S. Geological Survey, Baby powder, Fact Sheet FS-065-00, September 2000.

US National Library of Medicine (US-NLM). 2021. Fact about Talc. Retrieved from https://chem.nlm.nih.gov/chemidplus/jsp/toxnet/chemidplusfs.jsp on January 25, 2021.

Wentzensen N; Wacholder S. (2014). Talc use and ovarian cancer: epidemiology between a rock and a hard place. J Natl Cancer Inst. 106:1-2. 